\title{
Editorial Note: Next Applications for Multimedia Computing
}

Published online: 9 January 2019

(C) Springer Science+Business Media, LLC, part of Springer Nature 2019

Multimedia Tools and Applications gratefully acknowledges the editorial work of the scholars listed below on the special issue entitled, "Next Applications for Multimedia Computing."

Of 21 papers submitted to this issue, 9 were eventually accepted after a stringent peer-review process.

\section{Shingchern D. You}

National Taipei University of Technology, Taiwan

you@csie.ntut.edu.tw

\section{Hsiao-Chun Wu}

Division of Electrical and Computer Engineering

School of Electrical Engineering and Computer Science

Louisiana State University, USA

hwu1@1su.edu

\section{Xiaokang Zhou}

Department of Data Science

Shiga University, Japan

zhou@biwako.shiga-u.ac.jp

Publisher's Note Springer Nature remains neutral with regard to jurisdictional claims in published maps and institutional affiliations. 